\title{
Inovando para o consumo sustentável: $O$ desafio na construção de um novo paradigma organizacional
}

\author{
Innovating for sustainable consumption: The challenge in building a new organizational \\ paradigm
}

Minelle E. Silva

Universidade Federal de Pernambuco

e-mail: minele.adm@gmail.com

Ana Paula Machado Corrêa

Universidade Federal de Pernambuco

Carla Pasa Gómez

Universidade Federal de Pernambuco

Artigo Recebido em 19.07.2011. Revisado por pares em 12.11.2011. Recomendado em 12.11.2011 por Edson Roberto Scharf, Editor Responsável. Publicado em 30.06.2012. Organização responsável pelo periódico: FURB Universidade de Blumenau (www.furb.br/rn)

\begin{abstract}
Resumo
Ao longo dos últimos anos, as evidências das crises ambientais, sociais e econômicas indicam a necessidade de mudança do paradigma desenvolvimentista vigente. Nesse contexto e tendo em vista a continuidade da sobrevivência humana, as ideologias devem ser substituídas e os padrões de consumo modificados. Para tal, os papéis dos stakeholders na relação inovação-produção-consumo devem ser revistos, e atores primordiais como governo, sociedade e empresas devem assumir suas funções na transformação do paradigma. Na busca do desenvolvimento sustentável, o presente ensaio foca sua atenção na empresa e tem por objetivo compreender como a inovação empresarial fornece suporte para o consumo sustentável. Nesse trabalho os recursos e processos organizacionais, tais como estratégia, tecnologia, Pesquisa e Desenvolvimento (P\&D), logística, gestão de pessoas e a análise do ciclo de vida do produto, são tidos como ferramentas operacionais da inovação para o alcance de um consumo sustentável. Porém, sabe-se que apenas as inovações socioambientais empresariais não são suficientes para a promoção do consumo sustentável, é preciso o envolvimento dos demais atores na busca de um modelo de desenvolvimento sustentável, que
\end{abstract}

permita tanto o crescimento da economia de forma eficiente, quanto à equidade social e o equilíbrio ambiental.

Palavras-chave: Consumo Sustentável; Inovação; Responsabilidade Socioambiental.

\begin{abstract}
Over recent years, evidence of environmental, social and economic crises indicate the need for paradigm shift developmental force. In this context

and in view of the continuity of human survival, ideologies must be replaced and consumption patterns changed. To this end, the roles of stakeholders in relation innovation-productionconsumption should be reviewed, and primary actors such as government, society and companies should assume their roles in the transformation of the paradigm. In pursuit of sustainable development, this paper focuses its attention on the company and objectives to understand how business innovation provides support for sustainable consumption. In this study the resources and organizational processes such as strategy, technology, research and development (R \& D), logistics, personnel management and analysis of the life cycle of the product, are taken as operational tools of innovation to achieve
\end{abstract}


sustainable consumption. However, it is known that only the social and environmental corporate innovations are not sufficient to promote sustainable consumption, we need the involvement of other actors in pursuit of a sustainable development model that allows both the growth of the economy efficiently, as the social, equity and environmental balance.

Key-words: Sustainable Consumption; Inovation; Social-Environment Responsibility.

\section{Introdução}

Em meio às transformações mundiais que vem ocorrendo continuamente, nos diferentes âmbitos de atuação humana, percebe-se a emergência de fatores que interferem de forma direta nas atitudes e ações da população sobre o meio, sejam eles: sociais, econômicos ou ambientais. Tais mudanças indicam cada vez mais a necessidade de redirecionamento da prática capitalista atual, focada no individualismo, para uma que consiga abranger aspectos mais coletivos e de interesses mais amplos, proposta pelo desenvolvimento sustentável.

A mudança no paradigma desenvolvimentista sugere uma nova visão de todos os atores sociais no sentido de alteração das práticas até então adotadas pela compreensão, incorporação e atitudes mais holísticas, condição essencial para que os indivíduos compreendam e percebam os resultados positivos dessas transformações. O desenvolvimento sustentável considera a necessidade de continuidade tanto das gerações atuais como das futuras, no atendimento de seus anseios, por meio da harmonização entre as dimensões fundamentais: social, econômico e ambiental (SACHS, 2007).

A partir dessa visão, ações devem ser realizadas de forma concomitante ao estabelecimento desse paradigma de modo que o mesmo possa ser efetivado. Tais práticas envolvem um papel mais ativo do governo, uma responsabilidade socioambiental das empresas, bem como uma maior consciência individual ao modificar suas atitudes enquanto integrante da socie-dade. Essas práticas atendem aos requisitos do desenvolvimento sustentável, pela prá-tica de um consumo sustentável (PNUMA, 2001).

Entendendo que existe uma dicotomia entre a produção e a necessidade de mudança nas práticas de consumo, a ideia de consumo sustentável surge como um fator basilar para o desenvolvimento sustentável, na medida em que dentre as relações de complexidade que o mesmo assume, visualizam-se mudanças significativas entre os diferentes atores sociais envolvidos. Dentre esses atores, as empresas surgem como as detentoras de um importante papel nesse processo ao fornecer produtos e serviços mais sustentáveis.

Utilizando-se de inovações, de diferentes formas, os resultados empresariais dão o suporte para que a consciência do indivíduo, sem descartar a ideia de influência governamental no processo, possa vir a efetivar o consumo sustentável. Como afirma Porter e Van der Linde (2003, p.395) "as empresas dispõem de condições para adquirir insumos de baixo custo em qualquer lugar e as novas tecnologias, em rápido desenvolvimento, são capazes de compensar desvantagens no custo dos mesmos", indicando assim a capacidade de transformar os custos de investimentos em inovação para a susten-tabilidade em vantagens competitivas.

Segundo Barbieri (2007, p.99) "inovações representam mudanças, rupturas e incertezas que serão tanto maiores quanto maiores as novidades e a abrangência dos seus impactos sobre os elementos que compõem as dimensões da sustentabilidade associada ao desenvolvimento". Nesta perspectiva, as empresas que conseguem ponderar suas ações com a inserção de práticas inovadoras para o desenvolvimento sustentável estão assumindo sua responsabilidade nesse sentido e conseguindo apresentar uma nova forma de atuação. 
Ao mesmo tempo em que essas inovações começam a modificar de forma macro os aspectos relacionados ao novo modelo de desenvolvimento proposto, as empresas estão envolvidas na modificação das práticas de consumo da população, ao desempenhar o seu papel de fornecedor de produtos ou serviços sustentáveis. Assim sendo, considerando-se as demais características circundantes, entende-se que essas inovações podem favorecer ainda a efetivação do consumo sustentável de forma direta.

Com o intuito de identificar essas possíveis relações até então verificadas e na busca pela efetivação do papel empresarial na nova prática do modelo desenvolvimentista, o presente estudo tem como objetivo compreender como a inovação nas organizações pode auxiliar ao alcance do consumo sustentável, considerando que existem as influências dos outros atores sociais nesse sentido. Assim, torna-se relevante reconhecer e interrelacionar os constructos envolvidos com o pressuposto, no sentido de gerar um melhor entendimento da proposta abor-dada.

\section{Referencial Teórico}

\subsection{O paradigma do Desenvolvimento Sustentável}

Levando em consideração as constantes mudanças que estão ocorrendo em todo o mundo, sejam elas econômicas, sociais ou ambientais, fica perceptível que tais transformações são o reflexo das ações humanas sobre o meio ambiente, as quais podem ser percebidas por meio das mudanças climáticas, das economias abaladas, bem como pelo impacto social resultante desse processo. As atitudes individuais em relação à coletividade, em sua maioria, direcionam seus holofotes para os aspectos intrínsecos a cada um, focalizando as prioridades e disponibilidades que são percebidas.
Cada vez mais se percebe a necessidade de mudança na forma de desenvolvimento ao qual se está submetido, por entender que o pensamento capitalista traz a ideia de abundância de recursos, bem como incentiva as práticas individualistas causando dentre outras consequências a intensificação do consumismo, ou seja, aquele consumo extravagante de bens e serviços (GIACOMINI FILHO, 2008). Deve-se buscar, portanto, mudar a visão de um desenvolvimento "feroz" com o foco na riqueza, para um novo meio, mais "amigável" com uma combinação de atividades harmônicas (SEN, 2000), em que de fato a "tragédia dos comuns" (HARDIN, 1968) seja compreendida.

Para que uma mudança de paradigma possa ser posta em prática, o desafio mais importante, segundo Ray (1999, p.21), "consiste em aplicar o conhecimento interior, a intuição, a compaixão e o espírito a prosperidade, num período de mudança constante e descontínua", ou seja, se faz necessária uma incorporação de questões referentes a assuntos específicos como a capacidade de inovação que as organizações podem desenvolver, considerando que a nova visão deve seguir um pensamento distinto do praticado de forma que haja uma continuidade dessas ações.

O desenvolvimento sustentável surge, nesse sentido, como alternativa a essa necessidade de mudança, em se considerando que um conjunto de ações deve ser praticado para a efetivação do mesmo. Seu conceito mais completo foi definido no Relatório de Brundtland, no qual é entendido como "um processo de mudança em que a exploração dos recursos, a direção dos investimentos, a orientação do desenvolvimento tecnológico e a mudança institucional estão todos em harmonia" para que as necessidades humanas possam ser satisfeitas atualmente e no futuro (WCDE, 1987). 
De fato, o direcionamento das atividades para uma nova forma de prática organizacional necessita de uma "mudança no pensamento mecanicista para o sistêmico, e de um sistema de valores baseado na dominação para um sistema baseado na parceria" (CASAGRANDE JR, 2003, p.3), indicando que o novo modelo alternativo a ser praticado serve como subsídio para as ações organizacionais, ao verificar o surgimento de uma perspectiva pautada na harmonização de três critérios fundamentais, quais sejam: equidade social, eficiência econômica e equilíbrio ambiental.

Tal mudança, para Sachs (2007), consegue designar ao mesmo tempo o surgimento de um novo estilo de desenvolvimento - por meio da percepção de que outra forma de desenvolvimento pode tornar-se subsídio para a manutenção da sociedade - e um novo enfoque de planejamento e gestão, no qual as práticas atuais redirecionam suas ações para questões mais holísticas e coletivas demonstrando um diferente papel a ser praticado.

A mudança de paradigma desenvolvimentista relaciona-se com a modificação na cultura social, nas práticas de consumo da população, na forma de atuação das organizações (públicas e privadas) de maneira tal que são necessárias ações de longo prazo. Fato este corroborado por Schumacher (2001) quando afirma que o problema deve ser entendido em sua totalidade, buscando reconhecer e desenvolver um novo estilo de vida, com novos métodos de produção e novos padrões de consumo.

Ao longo das últimas décadas, intensificaram-se as discussões sobre como modificar essa tendência negativa a qual o mundo está se direcionando. Desta forma, pode-se levantar questionamentos sobre a melhor maneira de se alcançar a harmonia entre esses critérios fundamentais do desenvolvimento sustentável: Quem são realmente os responsáveis pela atual situação mundial? Numa perspectiva de mudança dessa situação, será que a responsabilidade deve ser direcionada apenas aos gestores públicos? Será que as organizações - empresas - são as principais responsáveis? Ou será que a sociedade, por meio de cada indivíduo ou organização civil possui papel fundamental nesse processo de reestruturação rumo a um desenvolvi-mento sustentável mundial?

Apesar de se apresentar como uma questão ampla na qual, normalmente, direciona-se toda a responsabilidade de seu alcance ao Estado, é notável a necessidade de que toda a sociedade se envolva em harmonizar as dimensões básicas do desenvolvimento sustentável no sentido de que se consiga usufruir os recursos necessários da melhor maneira possível para a continuidade tanto das gerações atuais como das futuras, no atendimento de suas necessidades. Tal fato é citado por Buarque (2008) como a solidariedade intra geracional e inter geracional, respectivamente.

Deste modo, na busca pela manutenção dessa solidariedade, fato essencial para o desenvolvimento sustentavel, percebe-se que além do Estado, cada empresa, organização do terceiro setor e indivíduo - sociedade - deve tornar-se consciente de seu papel na busca pelo desenvolvimento sustentável (Figura 01), uma vez que a mudança na forma de atuação posta em prática é o ponto de partida inicial para que se consiga atingir um desenvolvimento endógeno, auto-suficiente, orientado para as necessidades, em harmonia com a natureza e aberto às mudanças institucionais (SACHS, 2008). 


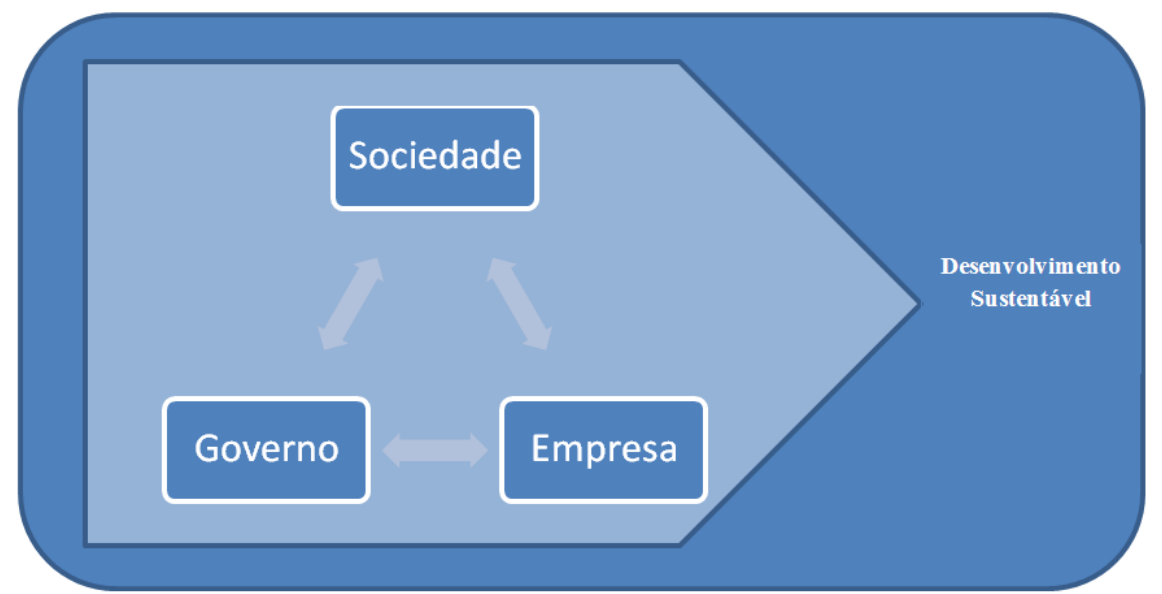

Figura 1- Relações sociais para o desenvolvimento sustentável Fonte: Os autores

Como se pode perceber na ilustração, as relações sociais que permeiam o alcance do desenvolvimento sustentável indicam que todos, sem exceção alguma, possuem co-responsabilidade no processo de mudança paradigmática, ao compreender que suas ações em relação a sua área de atuação devem estar condizentes com o novo modelo de desenvolvimento que está sendo defendido. Desse modo, o governo (Estado), as empresas e a sociedade (indivíduos e organizações do terceiro setor) podem direcionar suas práticas para a efetivação desse paradigma, ou seja, da nova forma de visualizar tais relações.

O Estado, pelas atribuições que lhe são concedidas deve direcionar seus esforços em diferentes vertentes, no sentido de auxiliar o alcance do desenvolvimento sustentável, dentre as quais se pode afirmar que o papel do governo está em regular e fiscalizar as atividades gerais que estejam desviadas desse objetivo, bem como financiador e fomentador no surgimento de alternativas capazes de sustentar a ação humana quanto ao meio ambiente, no sentido de melhor organizar a sociedade.

Tal aspecto envolve um maior empenho público rumo ao desenvolvimento sustentável, já que o mesmo deve ter a percepção de que suas ações podem interferir diretamente nas práticas sociais, pois a curto, a médio e a longo prazo suas ações refletirão num desenvolvimento benéfico para a coletividade mundial. Kiperstok et al. (2002) afirmam que a legislação apresenta-se como reflexos a visão que a sociedade tem em um determinado momento, dessa forma torna-se cada vez imprescindível a mudança de atitude da coletividade quanto ao novo modelo de desenvolvimento.

Outro ator social importante para o alcance do desenvolvimento sustentável é reconhecido como organizações com finalidades lucrativas, ou simplesmente empresa. A sua atuação está condicionada à busca pela harmonização no caráter de atuação e na abrangência na realização de suas atividades (BORGER, 2006). Fato este que pode ser efetivado pela equivalência das dimensões básicas do desenvolvimento sustentável ao conceito de sustentabilidade em organizações (BARBIERI e CAJAZEIRA, 2009). Práticas mais coletivas demonstram o caráter socialmente responsável de uma empresa junto à população local.

Para Porter e Van der Linde (2003, p.395) é "importante utilizar os recursos de forma produtiva, sejam eles naturais e físicos ou humanos e de capital". Dessa maneira com a reestruturação no processo produtivo organizacional, a empresa consegue se comprometer com o alcance do 
desenvolvimento sustentável, haja vista que dentro de suas especificações a forma como ela pode contribuir perpassa suas práticas e processos de produção. Fato este que para Barbieri et al (2010), deve estar condicionado a uma forma de atuação para, no mínimo, em se considerando a perspectiva econômica, reduzir os impactos sócioambiental adversos.

Os autores afirmam ainda, que nessa atuação direcionada ao desenvolvimento sustentável as inovações desenvolvidas nas organizações passam a possuir critérios de avaliação além dos convencionais, indicando que não apenas os seus resultados enquanto aspecto financeiro receberá um retorno positivo, mas também a coletividade recebe mesmo que indiretamente retornos positivos dessa nova prática organizacional. Nesta perspectiva, Hart (2006, p.212) afirma ser necessário sair da camisa-de-força atual, com pesquisa e desenvolvimentos centralizados, para que se consiga realizar a modificação tanto no que concernem as tecnologias utilizadas como em relação ao modelo de negócios praticado.

O terceiro setor, pelo seu papel contributivo na solução de problemas sociais e em prol do bem comum, pode ser considerado um dos atores sociais mais significativos na mobilização da sociedade para às questões de desenvolvimento sustentável. Portanto, a sustentabilidade de suas ações também está condicionada a essa harmonização das dimensões da sustentabilidade, todavia adaptada ao caráter não lucrativo do setor. Entendendoo como movimento social por distintas causas, o posicionamento das organizações no setor de maneira duradoura auxiliando ao desenvolvimento sustentável, pode se dar por suas atividades previamente estabelecidas e desenvolvidas com um caráter de continuidade.

Como outro ator social, pertencente à sociedade, o indivíduo em sua singularidade, é capaz de promover mudanças no padrão de produção a partir da sua decisão de consumo, a qual se apresenta atualmente com um estilo de vida populacional e padrões de consumo incompatíveis com a possibilidade de um desenvolvimento sustentável. De certo modo, cada indivíduo tem condições de reestruturar a maneira como age na sociedade, uma vez que possui um poder de influência sobre as ações das demais instituições supracitadas.

Para, Gomes (2007) a atuação do consumidor no mercado pode ter reflexos positivos ou negativos sobre a economia, o meio ambiente e o comportamento das empresas. Desta feita, percebe-se que quanto mais informados sobre a melhor maneira de agir, os cidadãos (muitas vezes visualizados apenas como consumidores) assumem um papel de destaque, na busca pelo desenvolvimento sustentável, e necessitam ser melhor compreendidos, ao entender que a partir do momento em que este começa a se portar como consumidor consciente, politizado e preocupado com as questões coletivas, torna-se cada vez mais próximo a efetivação dessa mudança.

Compreendendo a influência do governo e da sociedade sobre as empresas intensifica-se a relação inovação-produçãoconsumo para o desenvolvimento sustentável a partir de recursos e processos organizacionais, tais como estratégia, tecnologia, Pesquisa e Desenvolvimento (P\&D), logística, gestão de pessoas e a análise do ciclo de vida do produto, tidos como ferramentas operacionais da inovação. Essas esferas, no entanto, não são analisadas de maneira isolada, percebem-se as interrelações e influências existentes.

Considerando o foco temático do presente estudo, o qual permeia as questões de processos sustentáveis, por meio de uma responsabilidade socioambiental empresarial junto a sociedade, bem como no que concerne os aspectos pertinentes ao consumo sustentável, o qual se efetiva por um conjunto de relações sociais a luz do desenvolvimento sustentável, é de suma 
importância realizar um aprofundamento quanto a esses constructos, por entender que a proposta de estudo indica uma relação tênue entre os mesmos.

\subsection{Responsabilidade Socioambiental Empresarial}

As discussões referentes à responsabilidade social começaram a ser realizadas a partir do reconhecimento das questões pertinentes ao papel social que uma empresa possui dentro do contexto a qual esta inserida. Essa teoria considerava inicialmente como única responsabilidade das empresas (FRIEDMAN, 1970). Tal fato evoluiu ao longo do tempo onde passou-se a identificar o interesse de outros envolvidos pelos e nos processos empresariais por seus resultados ganhando força assim a Teoria dos Stakeholders proposta por Freeman (1984).

Nesse sentido, Pasa (2004) indica que a Responsabilidade Social Empresarial (RSE) surge como um novo paradigma empresarial em função do modelo de desenvolvimento sustentável proposto, no qual os negócios empresariais trazem para sua gestão as expectativas e pressões dos atores interessados e/ou afetados stakeholders - nos processos organizacionais. Nascimento et al. (2008) ratificam o posicionamento da autora em relação ao debate da necessidade de se considerar esses envolvidos na tomada de decisão empresarial.

Para o Instituto Ethos (2009) a responsabilidade social empresarial pode ser definida como a "forma de gestão que se define pela relação ética e transparente da empresa com todos os públicos com os quais se relaciona e pelo estabelecimento de metas empresariais compatíveis com o desenvolvimento sustentável". Essa ideia é corroborada por Laville (2009) ao indicar ser de responsabilidade da empresa resolver os inúmeros danos e problemas por ela causados que atingem a sociedade.
Elkington (2001) indica ser necessário guiar as empresas na direção da sustentabilidade com a mudança no desempenho das mesmas nas dimensões econômica, ambiental e social, surgindo a chamada Responsabilidade Socioambiental Empresarial (RSAE), haja vista o envolvimento da empresa com as práticas sociais e ambientais, e considerando ainda o caráter lucrativo a qual o mesmo está submetido.

A responsabilidade socioambiental, portanto, deve ser entendida como uma extensão na forma de gerenciamento que as organizações devem adotar a partir da ideia de atuação como negócio sustentável (KRUGLIANSKAS et al., 2009). Tal aspecto está relacionado à adoção de estratégias de negócios e atividades que atendam as necessidades da empresa e de seus stakeholders, para Barbieri e Cajazeira (2009), de modo que envolva uma relação mútua de interesses com vistas a um objetivo maior, qual seja: o desenvolvimento sustentável.

A organização é constituída por uma grande quantidade de atividades responsáveis pelo desenvolvimento empresarial. Desse modo, percebe-se que as funções de estratégia, logística, recursos humanos, pesquisa e desenvolvimento, tecnologia, ciclo de vida do produto, possuem atribuições específicas nas organizações quanto à busca pela prática de responsabilidade socioambiental.

Cada uma das funções assume a responsabilidade de minimizar os impactos ambientais e sociais em seus processos, assim como permitir que o produto/serviço final permita a promoção das dimensões da sustentabilidade. E uma das atividades que podem ser desenvolvidas, nesse sentido, está relacionada a práticas inovativas empresariais direcionadas a melhora do desempenho organizacional em relação às questões sustentáveis, uma vez que a empresa é definida como um importante ator social para tanto. Tais práticas podem facilitar a efetivação de um novo padrão de 
consumo na sociedade, em meio a questões mais globais, o qual pode ser reconhecido como consumo sustentável, preocupado com a continuidade do ser humano no planeta.

\subsection{Consumo Sustentável}

A prática do consumo acompanha o ser humano em todos os momentos, direta ou indiretamente, ratificando ser indissociável viver sem consumir. Entretanto, a evolução na dinâmica econômica praticada atualmente, bem como a constante prática individualista que está sendo incentivada, demonstra a necessidade que a sociedade de consumo em que se vive redirecione seu foco para outro caminho, no qual se possa compreender que é impossível manter a prática de consumo, dada as condições atuais de exploração dos recursos naturais e seu esgotamento.

No debate acerca do consumo, percebe-se a falta de consenso na definição do que vem a ser consumo sustentável, muitas vezes confundido com o consumo consciente focado apenas no indivíduo. Essa confusão abre uma lacuna teórica tratada na discussão do presente estudo. É possível perceber cada vez mais a necessidade de se realizar o estabelecimento de um novo modelo de consumo que venha substituir a prática insustentável atual e que seja aceitável para toda a população trazendo melhores condições de vida de forma abrangente e favorável para a continuação dos vários atores sociais no planeta (PNUMA, 2001). Assim como é necessário mudar o paradigma de desenvolvimento, o paradigma do consumo também precisa de um redirecionamento.

Entendendo que há uma relação direta entre a prática do consumo e a forma de desenvolvimento adotada pelas nações, pode-se afirmar que um dos objetivos para o alcance do desenvolvimento sustentável se dá por meio da mudança nos padrões de consumo, ao perceber a necessidade de "promover padrões de consumo e produção que reduzam as pressões ambientais e atendam às necessidades básicas da humanidade" (AGENDA 21, 1992). Partindo desse princípio, torna-se possível a busca pelo consumo sustentável. Diante dessas considerações, o consumo sustentável analogamente ao conceito de desenvolvimento sustentável pode ser considerado como a prática de consumo que utiliza os recursos naturais para satisfazer as necessidades atuais, sem comprometer as necessidades e aspirações das gerações futuras (BEDANTE, 2004; GOMES, 2006; COSTA E OLIVEIRA, 2009; CORTEZ e ORTIGOZA, 2007).

Paralelamente existe essa preocupação inter e intra geracional também com relação à continuidade da prática de consumo, todavia faz-se necessário compreender que para a efetivação sustentável desse consumo há uma complexidade de relações que permeiam a dinâmica de mercado. Assim sendo, para Portilho (2003) o consumo sustentável surge como uma nova perspectiva em relação às estratégias públicas quanto à esfera do consumo, as novas formas de produção das empresas, bem como as mudanças comportamentais dos indivíduos no mercado. Refere-se a uma nova forma de atuação em todas as esferas, sejam elas econômicas, sociais e políticas, representados genericamente pelo governo, a indústria (empresas), bem como pela sociedade, ou seja, por cada indivíduo-cidadão que possua o entendimento quanto a essa prática (CORTEZ e ORTIGOZA, 2007; PANAROTTO, 2008).

Assim sendo, o consumo sustentável pode ser definido, segundo Silva (2010, p.8), como “o padrão de consumo resultante das inter-relações entre os atores sociais (Governo-Empresa-Sociedade) direcionado ao alcance do desenvolvimento sustentável", devendo cada um desses atores assumir papéis e obrigações distintas direcionados ao consumo sustentável. Os governos deverão promover e facilitar o desenvolvimento de tecnologias limpas, 
bem como transferi-las e adotá-las. Tem o papel ainda de apoiar pesquisas para o fornecimento de informações de produção e consumo, tanto para a indústria como para os consumidores (PNUMA, 2001). De fato, é imprescindível que o governo assuma o seu papel entendendo que por meio, por exemplo, de políticas públicas e programas educacionais conseguirá desenvolver ou incentivar outros atores para a tais práticas sustentáveis.

O papel da indústria, ainda segundo o PNUMA (2001), está basicamente na adoção de práticas de responsabilidade socioambiental junto à coletividade, uma vez que dessa maneira a mesma consegue desenvolver uma produção sustentável, bem como práticas de aprimoramento para uma melhor atuação sua no mercado. Uma das propostas está na busca por soluções inovadoras que auxiliam mais rapidamente o alcance do consumo sustentável em função do modelo de desenvolvimento sustentável que se almeja.

$\mathrm{O}$ indivíduo, nesse momento, assume o papel mais importante no processo de definição da nova prática de consumo sustentável, ao desempenhar papel de consciência no momento da compra, bem como um comportamento de consumidor preocupado com as questões pertinentes ao desenvolvimento sustentável. Esse é o desafio fundamental para o movimento dos consumidores (PNUMA, 2001), uma vez que o indivíduo no meio em que se encontra recebe influências e pressões contra essa nova atitude e, na maioria das vezes, sucumbi à opção de não fazê-lo.

Visualizando o indivíduo como o principal responsável pelas transformações quanto à busca pelo consumo sustentável, torna-se necessário considerar características tais como: a cultura na qual essa sociedade do consumo está envolvida, o estilo de vida adotado, o poder aquisitivo da população, as questões éticas assumidas por cada um, bem como a educação a qual essa sociedade está sujeita para obter uma percepção sistemática da necessidade de se tornar mais consciente. Aspectos estes que estão diretamente relacionados com as obrigações dos outros atores supracitados e que demonstram a complexidade existente para tanto.

Apesar dessas considerações, vale ressaltar que nem todas as economias são iguais, para Tukker et al. (2008) cada uma das economias existentes - desenvolvidas, em desenvolvimento e base da pirâmide possuem especificidades que devem ser consideradas quando forem desenvolvidos programas de incentivo e regulamentação quanto a prática do consumo sustentável. Segundo os autores, o desafio para economias desenvolvidas é fazer mais com menos; para as economias em desenvolvimento está no processo de construção de estruturas sustentáveis para produção e consumo; já na base da pirâmide à primeira meta é criar uma base sustentável com crescimento equitativo e erradicação da pobreza.

Assim sendo, apesar de entender que são complexas as relações que devem ser desenvolvidas para que o consumo sustentável possa ser efetivado, pode-se dizer que aquela que apresenta uma das relações imprescindíveis é a produçãoconsumo. Apesar de o indivíduo possuir a consciência de sua responsabilidade para o desenvolvimento sustentável a oferta de produtos "sustentáveis" torna-se relevante na medida em que só se pode alcançar o consumo sustentável se houver o relacionamento efetivo entre os atores. Desse modo, uma das formas de realizar essa prática dá-se por meio da inovação.

\subsection{Inovação}

A atividade inovativa nas organizações envolve de forma simples o direcionamento organizacional para a utilização de oportunidades junto a novas práticas de negociação que venham a surgir no mercado. Saber utilizar suas competências para 
obter melhor desempenho, apresenta-se como um dos aspectos mais favoráveis para a organização, uma vez que segundo Porter e Van der Linde (2003) serão vencedoras apenas aquelas que inovarem com êxito.

Esse entendimento pode ser corroborado por Zen (2007) a partir do momento em que a inovação pode ser considerada como resultante de um processo de combinação de recursos e competências para gerar invenções e levá-las ao mercado. De fato se as organizações conseguem desempenhar de forma concisa essa combinação a mesma consegue diferenciar-se dos demais participantes do ambiente de negócio.

Para Sarkar (2008) uma inovação é entendida como algo bem mais do que ter ideias, e por isso, se faz necessário que essas sejam implementadas e tenham seu impacto econômico positivo para a organização. De forma complementar ela pode ser entendida como um processo que transforma as ideias surgidas de oportunidades em algo prático de uso extensivo (PLONSKI, 2005). Já Moreira e Queiroz (2007) entendem que a inovação está relacionada com a adoção de mudanças para a organização e para seu ambiente.

De forma mais assertiva, o conceito de inovação mais difundido indica que o mesmo pode ser considerado como a implantação de novos produtos ou significativamente melhorado em relação às necessidades dos clientes e consumidores (OCDE, 2003). Nesse sentido, como forma de operacionalizar a inovação, Tigre (2006) apresenta algumas formas mais utilizadas pelas empresas para realização de inovações, dentre as quais: desenvolvimento tecnológico próprio; conhecimento codificado; conhecimento tácito e aprendizado cumulativo, todas essas formas requerem um grande envolvimento organizacional nesse processo.

Por ser um conceito amplo o qual envolve modificações em todo o processo produtivo de uma organização, existem algumas variações quanto a tipologia da inovação, ao entender que a mesma pode ocorrer de formas bastante distintas ao direcionar-se a áreas específicas nas organizações. Os tipos de inovação mais difundidos na literatura são: produto, processo, organizacional e em marketing (OCDE, 2003; MOREIRA e QUEIROZ, 2007; SARKAR, 2008; TIDD et al., 2008), apresentando como características principais:

-Inovação em produto ou no serviço: definida como modificações nas potencialidades dos bens e serviços, bem como a mudança de suas características específicas, sendo considerado um aspecto agregador ou radical.

-Inovação no processo: caracterizada como a implantação de um método de produção novo ou significativamente melhorado, que envolve técnicas, equipamentos e software que auxiliarão na produção de bens e serviços.

-Inovação organizacional: realiza modificações radicais ou incrementais nos processos de práticas de negócios na empresa, interna ou externamente, visando a melhoria no fluxo das atividades organizacionais.

-Inovação em marketing: caracterizada pelas transformações nos aspectos que envolvem vendas, distribuição, embalagem, além da promoção e fixação de preço, para atender a diferentes necessidades dos clientes e possíveis consumidores.

As inovações nas organizações podem assumir, além dessas quatro supracitadas, novas caracterizações de acordo com as práticas a serem realizadas. Segundo Moreira e Queiroz (2007) existe a inovação nas pessoas quando podem ser mudados o comportamento ou as crenças das pessoas dentro da organizações, via técnicas de educação e treinamento. Outra inovação que pode ser observada diz respeito à inovação na estrutura organizacional ou na gestão ao modificar as 
práticas de gestão utilizadas (SARKAR, 2008).

Surgem ainda outros dois tipos de inovação, a de posição e a de paradigma. De acordo com Tidd et al. (2008), a primeira refere-se a mudança no contexto em que os produtos ou serviços são introduzidos, estão relacionadas ao reposicionamento da percepção sobre esse produto/serviço. Já a segunda inovação citada, está relacionada à mudança nos modelos mentais subjacentes que orientam o que a empresa faz.

Considerando que diante das mudanças que vem ocorrendo no ambiente de negócios, no qual cada vez mais se faz necessário o direcionamento das atividades organizacionais para o alcance de uma nova forma de desenvolvimento, preocupado com a continuidade das atividades e com a sustentabilidade do planeta, a inovação pode ser utilizada como a ligação direta entre o mercado consumidor e o desenvolvimento sustentável se a inovação for sustentável (BARBIERI et al., 2010).

Segundo Barbieri (2007, p.105) uma organização inovadora sustentável "não é aquela que introduz novidades de qualquer tipo, mas novidades que atendam as múltiplas dimensões da sustentabilidade em bases sistemáticas e colham resultados positivos para ela, pra a sociedade e o meio ambiente". Para Casagrande Jr (2003) esta pode acontecer pela utilização de estratégias de transição construídas sob uma plataforma de práticas interdisciplinares.

Outra forma de utilização da inovação para as questões sustentáveis denomina-se por eco-inovação. Ela pode ser desenvolvida por firmas ou organizações sem finalidade lucrativa, podendo ser negociadas no mercado ou não, no qual sua natureza pode ser tecnológica, organizacional, social ou institucional (RENNINGS, 2000). Tal prática, ainda segundo o autor, pode ser direcionada para o consumo sustentável, por suas caracterí- sticas macro que envolve uma gama de atores sociais sinergicamente.

\section{Inovações para o consumo sustentável}

Diante das mudanças no ambiente de negócios, cada vez mais torna-se interessante para as organizações garantir bom posicionamento no mercado, e por isso as empresas procuram mecanismos de inovação que proporcionem maior eficiência, possibilidade de desenvolvimento de novos produtos e criação de valores para o cliente (PORTER e VAN DER LINDE, 2003). Dessa forma, Kiperstok et al. (2002, p.9) afirmam que a inovação é orientada pelo mercado, regulamentação, padrão dos produtos e processos tecnológicos utilizados, o que força a empresa a inovar de acordo com outros aspectos se não $o$ econômico.

Nesta perspectiva, torna-se relevante identificar a maneira como essas inovações auxiliam do processo de efetivação do desenvolvimento sustentável, ao facilitar dentre outras coisas o alcance do consumo sustentável e indicar que diferentemente do que é observado atualmente, as ações organizacionais estão relacionadas com as responsabilidades que as empresas possuem em relação a concretização do novo modelo de desenvolvimento.

Compreende-se, sob esse ponto de vista, que os avanços resultantes de processos inovativos são fundamentais na formação de padrões de produção e consumo sustentáveis, de transformação da economia, além de seu desenvolvimento de longo prazo (LEMOS, 1999). Essas inovações, no entanto não estão restritas a mudanças na tecnologia utilizada, mas inclui também modificações em outros âmbitos organizacionais, tais como estratégia, gestão de pessoas, logística, ciclo de vida do produto, entendendo que dessa maneira suas ações estarão sendo desenvolvidas em consonância com outros objetivos macros, como visto a seguir: 


\section{- Estratégia}

As estratégias de organizações que buscam as questões sustentáveis segundo Hart (2006) não podem ser postas em prática até que a estrutura organizacional e os sistemas formais permitam isso. Para o mesmo autor uma das maneiras de alinhar a organização ao modelo defendido pelo desenvolvimento sustentável ocorre por meio da estratégia que tem por finalidade identificar o portfólio de valor sustentável, direcionando as atividades organizacionais para um objetivo maior referente a essa nova visão de negócios, efetivando desse modo inovações organizacionais, na estrutura e na gestão, o que facilitaria tal alcance.

De acordo com a estratégia que for adotada é possível analisar o grau de inovação a que uma organização se propõe. Por exemplo, quando as estratégias se direcionam mais para a dimensão econômica e objetivando a minimização dos impactos gerados pelo consumo dos produtos tem-se uma maior aproximação da visão Triple Bottom Line (ELKINGTON, 2001). No entanto, se as estratégias e práticas adotadas na tentativa de equilibrar as dimensões social, econômica e ambiental e têm início desde o design do processo, tem-se uma maior aproximação com a visão do Triple Top Line (MCDONOUGH e BRAUNGART, 2002) que tende a gerar produtos e processos com maior grau de inovação para o desenvolvimento sustentável.

Outro tipo de estratégia de inovação que aproxima a produção e o consumo e possibilitando um melhor comprometimento de ambas as partes com questões que levam ao desenvolvimento sustentável é descrito por Hawken et al. (1999) como Product Service System, que se baseia no aluguel do serviço, e não mais na venda de um produto, ou seja, as empresas passariam a vender soluções, cujo produto é por meio e não o fim. Para isso, elas seriam pagas para fornecer o serviço, bem como a responsabilidade pela manutenção e troca dos equipamentos. Sendo assim, o fabricante teria maior estímulo em produzir equipamentos que minimizassem a utilização de recursos, facilitasse sua manutenção e diminuísse o descarte. Tudo isso representaria tanto diminuição dos custos, como dos impactos ambientais, concebidas nos princípios do novo paradigma de consumo.

\section{- Análise de Ciclo de Vida do Produto - ACVP}

Uma das causas pelo crescente acúmulo de lixo na atualidade, além de resultante do consumo exacerbado e da falta de reaproveitamento de resíduos, se dá pelo ciclo de vida dos produtos que se encontra cada vez mais reduzido. Isso acontece, pois os produtos tornam-se obsoletos ou se danificam em um período de tempo curto, e em muitos casos o custo do concerto é maior do que a aquisição de um novo produto sendo, portanto, raramente consertados e descartados ou substituídos por outros (KAZAZIAN, 2005). Essa situação é mais impactante quando se trata de produtos tecnológicos, embora não se restrinja a essa área.

Segundo Razzolini Filho e Berté (2008) expandem essa abordagem e afirmam que cada etapa do ciclo de vida do produto, considerando desde a extração da matéria-prima até sua disposição final produz impactos sobre o ambiente, devem ser investigados pela ACVP. Seguindo essa linha, Vezzoli (2005) complementa afirmando que a ACVP trata-se de uma abordagem sistêmica, que permite identificar todas as consequências de um produto para concebê-lo de forma a minimizar os impactos gerados.

$\mathrm{Na}$ perspectiva do consumo sustentável a ACVP permite identificar e avaliar esses impactos e a partir daí auxiliar na formulação de estratégias que visem reduzi-los seja pela ampliação do 
ciclo de vida do produto que vai gerar menor descarte, ou pela aplicação de alternativas mais eficientes. $\mathrm{O}$ primeiro caso, associado à maior durabilidade do produto pode ser atingido por iniciativas como o favorecimento de ações de reparo e atualizações para diminuir a obsolescência ou procurar compor o produto de forma menos subordinada às modas. Já o segundo pode acontecer pela substituição de matéria-prima, tecnologia, processos de fabricação ou até de processos logísticos que proporcione maior eficiência do produto (KAZAZIAN, 2005; LEPRE, 2008).

Um novo modelo, segundo Casagrande Jr (2004) pode ser implantado quando a utilização de um design de baixo impacto ambiental se alia as práticas positivas da indústria. Portanto, pode-se esperar como resultado de atividade organizacional inovações em produtos, em processos, em posicionamento, bem como no paradigma ao qual a organização estará assumindo com a mudança de posicionamento.

\section{- Pesquisa e Desenvolvimento (P\&D)}

O P\&D é a área organizacional responsável não apenas por desenvolver novos produtos, mas também por realizar inovações nos já existentes em busca dentre outros objetivos, melhoria na produtividade. Desse modo, pode impactar positivamente para o alcance do consumo sustentável melhorando a eficiência na utilização de recursos, diminuindo consequentemente os resíduos industriais, evitando as perdas e ampliando a aceitação do consumidor (KRUGLIANSKAS et al., 2009), envolvendo modificações - inovação - diretamente em produtos e processos. Uma das ferramentas para tanto nessa área é o design.

Percebe-se, no entanto, que pelos profissionais desta área terem sido treinados em um paradigma tradicional, buscam apenas a integração de aspectos funcionais, econômicos, tecnológicos e culturais tendo como foco o aumento de vendas e de lucro (Casagrande Jr., 2004), não levando em consideração os aspectos que podem favorecer $o$ alcance do desenvolvimento sustentável, tais como o social e o ambiental. Em contraponto, surge o eco-design, na qual a preocupação com o desenvolvimento sustentável se faz presente desde a forma de conceber o produto buscando alternativas para reduzir os impactos ao mesmo tempo preservar e melhorar a qualidade do produto (KAZAZIAN, 2005).

Essa proposta pode ser percebida, por exemplo, por meio de ações para minimizar utilização dos recursos, escolha de recursos de baixo impacto ambiental, extensão do ciclo de vida ou através da utilização de componentes modulares que podem facilitar a reutilização de partes do produto (LEPRE, 2008). No entanto, a atividade de $P \& D$ deve ir além das preocupações com a concepção de produto, ou de mudanças layout, buscando investir em novos processos produtivos mais limpos na utilização de energias renováveis, direcionando esforços para inovações que estejam em compatibilidade com as novas necessidades socioambientais.

\section{- Tecnologia}

$\mathrm{Na}$ maioria das vezes Inovação e tecnologia são utilizadas como sinônimos, no entanto, como se pode observar a primeira é algo mais abrangente e pode ser percebida por vários aspectos, sendo a tecnologia apenas uma parte dessa dimensão. Sendo esta última entendida como sistemas e equipamentos utilizados para facilitar o fluxo de informações e a operacionalização das atividades de apoio, produção e comercialização de produtos. De forma restrita, Rogers (2003) afirma que inovação tecnológica está relacionada com as alterações do produto e seu benefício está associado com a vantagem relativa e a compatibilidade. A primeira 
seria a percepção de melhoria em relação à idéia substituída, e a segunda a compatibilidade percebida entre inovação, valores adotados e experiências passadas.

Esse tipo de estratégia concebida dentro dos princípios do Desenvolvimento Sustentável e de Tecnologias Apropriadas poderá ser de importante peso na definição de tecnologias-chaves em que o país deva investir, tanto para a resolução dos seus problemas ambientais básicos, como para um política de exportação de tecnologias, principalmente a países em desenvolvimento que contam com pouco capital para importar tecnologias caras de países industrializados (CASAGRANDE JR., 2003).

Hart (2006) foi ainda mais ousado ao atribuir grande responsabilidade da tecnologia na redução do impacto ambiental total (IAT) - função da população, da afluência, que representa o consumo, e da própria tecnologia - e no auxilio no alcance do desenvolvimento sustentável. Esse patamar pode começar a ser atingido pela adoção de mudanças tecnológicas, que possibilitem, por exemplo, o desenvolvimento de equipamentos e sistemas produtivos que se utilizem de menor quantidade de matéria-prima, de energia renovável e do reaproveitamento de produtos antes descartados.

De uma maneira geral, pode-se dizer que o progresso tecnológico está associado a mudanças sociais. O desenvolvimento produtivo, por exemplo, pode influenciar o desenvolvimento comercial e o consumo, que pode modificar a constituição social (BURNS e STALKER, 2001). No entanto, a influência das mudanças sociais e ambientais também pode levar a mudanças tecnológicas. Esse intercâmbio de influência, também possui relação de dependência, o que para Grossman e Helpman (1993), indica que os padrões de vida não podem crescer indefinidamente a menos que a tecnologia amplie a produção de recursos.

\section{- Gestão de Pessoas}

Os recursos humanos são os responsáveis por traduzir as estratégias empresariais em ação e, portanto, são fundamentais para o alcance dos objetivos da organização. A partir dessa afirmação pode-se inferir o caráter estratégico da gestão de pessoas, que deve estar associada com a questão de envolvimento desses colaboradores nas práticas organizacionais. Corroborando com essa idéia, Kruglianskas et al. (2009) afirmam que a forma como a empresa interage com seus colaboradores pode ter maior impacto sobre o comprometimento, empenho e satisfação do que um bom salário, e complementam dizendo que um bom ambiente de trabalho abre oportunidades para o crescimento e a sustentabilidade dos negócios. Assim é imprescindível ponderar que a necessidade de identificação dos anseios dos funcionários e o estabelecimento de objetivos organizacionais que os contemple (Almeida et al., 1993).

Para que a gestão de pessoas possa vir a ser um componente empresarial na promoção do consumo sustentável é preciso criar um sentimento de consciência coletiva que estimule comportamentos coerentes com os compromissos adotados pela organização (KRUGLIANSKAS et al., 2009). Esse processo de alinhamento e sensibilização pode ser desenvolvido por meio de oficinas e palestras com temas relacionados a inovação, ao desenvolvimento sustentável e seus desafios, que teriam como foco os executivos e que seriam disseminados por eles (LAVILLE, 2009).

A partir do momento que há esse vínculo mais forte entre a estratégia empresarial - voltada tanto para a inovação quanto para o desenvolvimento sustentável - e a identificação pessoal, os colaboradores podem atuar como promovedores de iniciativas internas e como desenvolvedores de ações que vão ter impactos 
externos ao envolver os clientes e a sociedade em geral. No entanto, para que essa contribuição aconteça e tendo em vista o alinhamento das ações organizacionais quanto à gestão de pessoas, Hart (2006) afirma ser necessário a integração da sustentabilidade com recrutamento, desenvolvimento de lideranças e avaliação de desempenho, com a qual os colaboradores vão estar preparados e estimulados a realizar a interface entre produção e consumo, com essa inovação nas pessoas.

\section{- Logística}

Com a dinâmica competitiva presen-te de forma enérgica no ambiente de negócios, é necessário a busca por serviços com maior qualidade e que satisfaçam as exigências dos clientes. Nessa perspectiva, a logística se apresenta como uma ferramenta que pode atuar como elo de ligação entre produção e consumo e agregar valor de tempo e localidade. Segundo Razzolini (2009, p.27) "o papel e a necessidade da logística determina-se pelas transformações ambientais, que exigem ou provocam mudanças nos paradigmas organizacionais para poder fazer frente às novas exigências do meio em que estas se situam". A atividade se configura pelo planejamento, produção e controle de materiais e informações do fabricante até o ponto de consumo.

No entanto, ao extrapolar os limites da empresa e passar a ter uma abordagem mais próxima e de maior comprometimento com as outras empresas a logística passa a ter uma nova concepção, conhecida como Supply Chain Management (SCM), entendida como o conjunto de empresas que procuram alinhar visões e objetivos em busca de gerar o maior valor para $o$ consumidor final, não se limitando a realizar melhorias isoladas, mas no sistema como um todo (BOWERSOX, 2001; FLEURY, 2000; PIRES, 2009). Por ter uma abordagem sistêmica e não pensar em ganhos isolados torna-se uma abordagem que não apenas insere os interessados na cadeia, como se aproxima de questões como sustentabilidade.

Embora do ponto de vista econômico e de relacionamento com o cliente os processos anteriores já demonstrem vantagens, a principal inovação da área dá-se pela logística reversa, uma abordagem recente que vem se desenvolvendo devido às pressões legislativas e a maior consciência ambiental da população. Semelhante a logística tradicional, diferese na direção do fluxo. Leite (2003) a define como "a área que planeja, opera e controla o fluxo e as informações logísticas do retorno dos bens de pós-venda e pósconsumo ao ciclo de negócios ou ciclo produtivo". Após percorrer os canais reversos, os produtos, componentes ou resíduos podem ter diferentes destinos: mercados secundários, reparo, renovação, re-manufatura, canibalização, reciclagem ou apropriada disposição (LEITE, 2003; RAZZOLINI FILHO e BERTÉ, 2008). Semelhantemente a eco-inovação envolve de atores para direcionar as externalidades organizacionais de maneira mais direcionada a melhores condições ambientais.

Diante das oportunidades e possibilidades de inovações supracitadas, percebe-se que uma organização considerada socioambientalmente responsável possui condições de contribuir para o alcance do consumo sustentável em um primeiro momento e, por consequência, a efetivação do desenvolvimento sustentável ao considerar a existência de seu importante papel nesse sentido. Desse modo, continuamente novidades e ideias devem ser desenvolvidas e praticadas no sentido de melhorar o desempenho tanto da empresa quanto da sociedade, em vista ao modelo desenvolvimentista proposto. Entendendo que esse papel organizacional não consegue efetivação se não houver a ação dos outros atores.

\section{Considerações Finais}


Ao analisar o contexto global, e se deparar com a desconjuntura estrutural que o mundo apresenta devido ao crescimento desproporcional e pelo fato de não proporcionar a devida importância para os aspectos ambientais e sociais percebe-se a necessidade de engajar os atores sociais aqui representados pelo governo, sociedade e empresa na modificação do modelo de desenvolvimento vigente. Como ponto crucial na mudança, o processo de inovação é tido como interativo, e realizado por meio da contribuição dos variados agentes econômicos e sociais, que possuem diferentes tipos de informações e conhecimentos (LEMOS, 1999).

Com o intuito de delimitar o objeto de estudo optou-se por destacar o papel da empresa e de suas práticas empresarias como fontes de inovação para a promoção do consumo sustentável. Foram apresentadas alternativas em diversas práticas e processos organizacionais com o intuito de demonstrar que uma empresa socioambientalmente responsável possui condições de realizar ações com uma maior preocupação com as questões sustentáveis, ao reestruturar seu processo produtivo de acordo com os princípios relacionados com a ideia de consumo sustentável apresentados.

Apesar dessas considerações, segundo Casagrande Jr. (2004) indica a necessidade de maiores incentivos a pesquisas científicas em diferentes áreas, tendo em vista o grande impacto que os produtos causam sob a perspectiva do desenvolvimento sustentável, e mais diretamente sob a prática do consumo sustentável. Desse modo, as altas taxas de inovações e mudanças exigidas pelo ambiente e consentidas pelas empresas dão origem a uma demanda por capacitação para responder às necessidades e oportunidades que surgem e exigem maiores investimentos em pesquisa, desenvolvi- mento, educação e treinamentos (LEMOS, 1999).

Assim sendo, assumindo o seu papel de co-responsável para a efetivação do consumo sustentável, as empresas podem utilizar-se das diferentes áreas organizacionais a depender de seus recursos, capacidades e competências com o intuito de contribuir em sua área de atuação para a criação de padrões de consumo mais sustentáveis, havendo a necessidade nesse momento de que a sociedade como um todo assuma também o seu papel e consiga apoiar esse processo de mudança rumo ao desenvolvimento sustentável.

\section{Referências}

AGENDA 21 - Capítulo 4. Mudança dos padrões de consumo. Conferência das Nações Unidas sobre Meio Ambiente e Desenvolvimento. 1992.

ALMEIDA, M. I. R.; TEIXEIRA, M. L. M.; MARTINELLI, D. P. Porque administrar estrategicamente recursos humanos? Revista de Administração de Empresas. São Paulo, 33 (2): 12-24. 1993.

BARBIERI, J. C. Organizações inovadoras sustentáveis. In: BARBIERI, J. C; SIMANTOB, M. Organizações inovadoras sustentáveis: uma reflexão sobre o futuro das organizações. São Paulo: Atlas, 2007.

BARBIERI, J. C.; CAJAZEIRA, J. E. R. Responsabilidade social empresarial e empresa sustentável. São Paulo: Saraiva, 2009.

BARBIERI, J. C.; VASCONCELOS, I. F. G.; ANDREASSI, Tales; VASCONCELOS, F. C. Inovação e sustentabilidade: Novos modelos e proposições. Revista de Administração de Empresas - RAE, v. 50, n. 2. São Paulo, 2010.

BEDANTE, G. N. A influência da consciência ambiental e das atitudes em relação ao consumo sustentável na 
intenção de compra de produtos ecologicamente embalados. 2004. $159 \mathrm{f}$. Dissertação (Mestrado em Administração) - Programa de Pós-Graduação em Administração. Universidade Federal do Rio Grande do Sul, Porto Alegre: 2004.

BORGER, Fernanda G. Responsabilidade Corporativa: a dimensão ética, social e ambiental na gestão das organizações. In: VILELA JÚNIOR, Alcir; DEMAJOROVIC, Jaques. Modelos e Ferramentas de Gestão Ambiental. São Paulo: Senac, 2006. p. 13-40.

BOWERSOX, D. J.; CLOSS, D. J. Logística empresarial: o processo de integração da cadeia de suprimento. São Paulo: Atlas, 2001

BUARQUE, S. C. Construindo o desenvolvimento local sustentável. 4 ed. Rio de Janeiro: Garamond, 2008.

BURnS, T.; STALKER, G. M. The management of innovation. New York: Oxford University Press, 2001.

CASAGRANDE JR; Eloy F. Inovação Tecnológica e Sustentabilidade: Possíveis ferramentas para uma necessária interface. CEFET - PR, 2004. Disponível em:

http://www.ppgte.cefetpr.br/selecao/2005/l eituras/casagrandeJr2004.pdf\#search='Eloy $\% 2 \mathrm{C} \% 20$ Casagrande $\% 2 \mathrm{C} \% 20$ alum $\% \mathrm{C} 3 \%$ ADnio\%2C\%20energia. Acesso jun. 2010.

CORTEZ, A. T. C.; ORTIGOZA, S. A. G. Consumo sustentável: Conflitos entre necessidades e desperdício. São Paulo: Editora UNESP, 2007.

COSTA, F. J.; OLIVEIRA, L. G. L. Produção e consumo sustentável: Um estudo de caso. In: Anais... XII Simpósio de Administração da Produção, Logística e Operações Internacionais - SIMPOI, 2009.

ELKINGTON, J. Canibais com garfo e faca. São Paulo: Makroon Books, 2001.
FLEURY, P. F. Supply Chain Management. In: FLEURY, Paulo F.; WANKE, Peter; FIGUEIREDO, Kleber F. Logística empresarial: a perspectiva brasileira. São Paulo: Atlas, 2000.

FREEMAN, R. E. Strategic management: a stakeholder approach. Boston, MA: Pitman, 1984.

FRIEDMAN, M. The social responsibility of business is to increase its profits. The New York Times Magazine, September 13, 1970.

GIACOMINI, G. F. Meio Ambiente \& Consumismo. São Paulo: Editora Senac São Paulo, 2008.

GOMES, D. V. Educação para o consumo ético e sustentável. Revista Eletrônica Mestrado em Educação Ambiental. v.16, jun 2006.

GROSSMAN, G. M.; HELPMAN, E. Innovation and growth in the global economy. MIT PRESS, 1993.

HARDIN, G. Tragedy of commons. Science, n.162, p.1243-1248, 1968.

HART, Stuart. O capitalismo na encruzilhada. Porto Alegre: Bookman, 2006.

HAWKEN, P.; LOVINS, A. e LOVINS, $H$. Natural Capitalism: creating the next industrial revolution. Little Brown - USA, 1999. Disponível em: http://www.natcap.org/. Acesso em: jul. 2010.

INSTITUTO ETHOS DE EMPRESAS E RESPOSANBILIDADE SOCIAL. O que é RSE. Disponível em: $<$ http://www1.ethos.org.br/EthosWeb/pt/2 9/o_que_e_rse/o_que_e_rse.aspx $>$. Acesso em: jan 2009.

KAZAZIAN, T. Haverá a idade das coisas leves: design e desenvolvimento sustentável. SP: SENAC SP, 2005.

KIPERSTOK, A.; COSTA, D. P.; ANDRADE, J. C.; AGRA, S. F.; 
FIGUEROA, E. Inovação como requisito do desenvolvimento sustentável. REAd Edição especial, v. 30, n. 6, nov. - dez. 2002.

KRUGLIANSKAS， I.; ALIGLERI, L.; ALIGLERI, L. A. Gestão socioambiental: responsabilidade e sustentabilidade do negócio. São Paulo: Atlas, 2009.

LAVILLE, E. A empresa verde. São Paulo: ÕTE, 2009.

LEITE, P. R. Logística reversa: meio ambiente e competitividade. São Paulo: Pearson Prentice Hall, 2003.

LEMOS, C. Inovação na Era do Conhecimento. In: LASTRES, H. M. M.; ALBAGLI, S. Informação e globalização na era do conhecimento. Rio de Janeiro: Campus, 1999.

LEPRE, P. R. Diretrizes para aplicação de dispositivos poka-yoke no design de mobiliário: uma estratégia para o design sustentável. 226 f. Dissertação (Mestrado em Design) - Programa de Pós-Graduação em Design. Universidade Federal do Paraná, 2008.

MCDONOUGH, W.; BRAUNGART, Michael. Design for the Triple Top Line: New tools for the sustainable commerce. Corporate Environmental Strategy, Vo. 9, n.3, 2002.

MOREIRA, D. A.; QUEIROZ, A. C (coords.). Inovação tecnológica e organizacional. São Paulo: Thomson Learning, 2007.

NASCIMENTO, L. F.; LEMOS, A. D. C.; MELLO, M. C. A. de. Gestão socioambiental estratégica. Porto Alegre: Bookman, 2008.

OECD. Manual de Oslo: diretrizes para coleta e interpretação de dados sobre inovação. Terceira Edição. Tradução FINEP, 2003.

PANAROTTO, C. O meio ambiente e o consumo sustentável: Alguns hábitos que podem fazer a diferença. Revista das relações de consumo. Caxias do Sul: 2008.

PASA, C. R. R. Modelo de avaliação da performance social empresarial. $277 \mathrm{p}$. Tese (Doutorado em Engenharia de Produção). Programa de Pós-graduação em Engenharia de Produção, Universidade Federal de Santa Catarina, 2004.

PIRES, S. R. I. Gestão da cadeia de suprimentos: conceitos, estratégias, práticas e casos. 2. ed. São Paulo: Atlas, 2009.

PLONSKI, G. A. Bases para um movimento pela inovação tecnológica no Brasil. São Paulo em Perspectiva, v. 19, n. 1, p. 25-33, jan./mar. 2005.

PNUMA - Programa das Nações Unidas para o Meio Ambiente. Rumo ao consumo sustentável na América latina e caribe. Workshop sobre consumo sustentável na América latina e caribe. São Paulo: 2001.

PORTER, M.; VAN DER LINDE, Class. Verde e Competitivo. In: PORTER, M. Competição: estratégias competitivas essenciais. Rio de Janeiro: Campus, 2003.

PORTILHO, M. F. F. O discurso internacional sobre consumo sustentável: possibilidades de politização e ambientalização da esfera privada. 2003. 170 p. Tese (Doutorado em Ciências Sociais) - Programa de Pós-Graduação em Sociologia. Universidade Estadual de Campinas, São Paulo, 2003.

RAZZOLINI, E. F. Logística: evolução na administração, desempenho e flexibilidade. Curitiba: Juruá Editora, 2009.

RAZZOLINI, E. F.; BERTÉ, R. O reverso da logística e as questões ambientais no Brasil. Curitiba: edição do autor, 2008.

RAY, M. Qual o novo paradigma nos negócios?. In: RAY, Michael; RINZLER, Alan (orgs). O novo paradigma nos negócios: Estratégias emergentes para 
liderança e mudança organizacional. São Paulo: Editora Cultrix, 1999.

RENNINGS, Klaus. Redifining inova-tion: Ecoinovation research and the contribution from ecological economics. Ecological Economics, v. 32. 2000.

ROGERS, E. M. Diffusion of innovations. 5. ed. New York: The Free Press, 2003.

SACHS, I. Rumo à ecossocioeconomia: Teoria e prática do desenvolvimento. São Paulo: Cortez, 2007.

Caminhos para o desenvolvimento sustentável. Rio de Janeiro: Garamond, 2008.

SARKAR, S. O empreendedor inovador: faça diferente e conquiste o seu espaço no mercado. Rio de Janeiro: Elsevier, 2008.

SCHUMACHER, E. F. Lo pequeno es hermoso. Espana: Tursen S.A, 2001.

SEN, A. K. Desenvolvimento como liberdade. São Paulo: Companhia das Letras, 2000.

SILVA, M. E. Consumo Sustentável: Em busca de um constructo. In Anais... XII Encontro Internacional sobre Gestão Empresarial e Meio Ambiente ENGEMA. São Paulo: FEA-USP, 2010.

TIDD, J.; BESSANT, J.; PAVITT, K. Gestão da inovação. 3. ed. Porto Alegre: Bookman, 2008.

TIGRE, P. B. Gestão da inovação: a economia da tecnologia no Brasil. Rio de Janeiro: Campus, 2006

TUKKER, A.; EMMERT, S.; CHARTER, M.; VEZZOLI, C.; STO, E.; ANDERSEN, M. M.; GEERKEN, T.; TISCHNER, U.; LAHLOU, S. Fostering change of sustainable consumptiom and production: an evidence based view. Journal of cleaner production, v. 16. 2008.

VEZZOLI, C. Il Design per la sostenibilità: una disciplina (sempre più) articolata, proceedings Formazione, sviluppo sostenibile e design: strumenti e strategie per la decade, Politecnico di Milano, Milan, 2005.

WCED - World Comission on Environment and Development. Report Our commom future. Genebra, 1987. Disponível em: <http://www.undocuments.net/wced-ocf.htm. $>$ Acesso em: jul. 2010.

ZEN, A. C. A influência dos recursos e das competências na inovação: Um estudo de múltiplos casos na indústria eletrônica gaúcha. 2007. 139 f. Dissertação (Mestrado em Administração) - Programa de Pós-Graduação em Administração. Universidade Federal do Rio Grande do Sul. Porto Alegre, 2007. 